Front. Educ China 2010, 5(3): 310-311

DOI $10.1007 / \mathrm{s} 11516-010-0102-2$

Special Issue Editorial

Jian Huang, Henning S. Olesen

\title{
East and West: Explorations in Research on Work and Learning
}

(C) Higher Education Press and Springer-Verlag 2010

In modern society, there is one particular relationship between work and learning which clearly stands out. "Learning in the workplace" is a specialized field of study which is new within educational science. Whether we look at the field of human resource development (HRD) emerged in 1970s in the United States, or examine the 1990s European and Commonwealth version, "Research on Work and Learning," the pivotal attention has been on learning activities in the workplace. Learning may improve the employee's work competences, promote their individual development, and result in the organization's competitive advantage within the globalized knowledge economy. In this way workplace learning has also become the central stage for analyses of and discussions about the role of lifelong learning in societal development on the whole.

This newly emerging field has also found a place within Chinese academia. With the dawn of the new century, the Chinese government has worked to increase the nation's qualified personnel and build stronger foundations in human resources. In 2007, the first Chinese HRD graduate program was established at East China Normal University in Shanghai. The group of young academics who founded the program initiated cooperation with international scholars, with this issue as a result.

We invited Canadian, Danish, German, and Chinese scholars to jointly investigate phenomena related to learning in the workplace in eastern and western cultural environments. From a research perspective, some papers explore

Jian Huang $(\bowtie)$

Institute of Vocational and Adult Education, East China Normal University, Shanghai 200062, China

E-mail: jhuang@ses.ecnu.edu.cn

Henning S. Olesen

Graduate School of Lifelong Learning Research, Roskilde University, DK4000 Roskilde, Denmark

E-mail: hso@ruc.dk 
the development of macro-theoretical concepts of HRD and of work life as a learning environment. At a micro-level, some others examine the work identity development of young students of caring professions during their education and in their subsequent transition to working life, and youth community self-identity in career development. In terms of methodology, two papers analyse the existing related literature, the others use qualitative research methodology to undertake empirical studies. Last but not least, from the theoretical point of view, the sample of articles reflects both experiences from North America, where managerial perspectives define the horizon of work related learning, and mainland European critical theory, influenced by a horizon of social welfare states and influential labour organizations. 